\title{
Algarada femenina en la posrevolución sonorense
}

\section{Female Uprising in the Post Sonoran Revolution}

\author{
Mercedes Zúñiga Elizalde* \\ (1) https://orcid.org/0000-0003-1212-0600 \\ El Colegio de Sonora, México \\ mzuniga@colson.edu.mx
}

Resumen: El artículo reflexiona sobre la acción política que algunas mujeres emprendieron en la arena pública durante la posrevolución sonorense, al involucrarse y tomar postura en los distintos conflictos que agitaron al estado en ese periodo. Interesa examinar las demandas que enarbolaron, los contextos en los que gestaron sus organizaciones y las alianzas que establecieron para fundamentar su participación en el espacio público y llegar, al cabo de los años, a dirigir sindicatos, ocupar puestos en la administración estatal, en los partidos políticos y en los cargos de elección popular una vez que se legisló el sufragio femenino en 1953. El texto es producto de un trabajo de archivo realizado durante varios años y pretende contribuir al conocimiento sobre la presencia y la acción pública de las mujeres en Sonora y en general a los estudios historiográficos sobre las mujeres que en la región se viene desarrollando recientemente.

Palabras clave: historia; mujeres; acción política; organización sindical; formas de participación.

* Doctora en Ciencias Sociales. Líneas de investigación: género y violencias, historiografía de las mujeres sonorenses.

cómo citar: Zúñiga Elizalde, M. (2022). Algarada femenina en la posrevolución sonorense. Secuencia (112), e1890. DOI: https://doi.org/10.18234/secuencia.v0i112.1890

c) Esta obra está protegida bajo una Licencia Creative Commons Atribución-NoComercial 4.0 Internacional. 
Abstract: This article reflects on the political action in which some women engaged in the public arena during the post-Sonoran revolution, by becoming involved and adopting positions in the conflicts that convulsed the state during that period. The article examines the demands they made, the contexts in which their organizations were created and the alliances they established to base their participation on the public space, which, over the years, eventually enabled them to lead unions and occupy positions in state administration, political parties, and popularly elected positions once women's suffrage had been legislated in 1953. The text is the result of archival work conducted over several years and seeks to contribute to knowledge about the presence and public action of women in Sonora and in general the historiographic studies on women recently undertaken in the region.

Keywords: history; women; political action; unions; forms of participation.

Recibido: 20 de julio de 2020 Aceptado: 17 de noviembre de 2020

Publicado: 10 de febrero de 2022

$\mathrm{D}_{\mathrm{t}}$ urante los años veinte y treinta del siglo $\mathrm{xx}$, una vez concluida la contienda armada más importante, múltiples espacios se abrieron para la acción política, particularmente para aquellos grupos de población mantenidos al margen de la toma de decisiones. En esta incursión pública se destacaron las mujeres, y al fragor de sus luchas activaron demandas e impulsaron distintas formas de organización y participación, posicionándose en las distintas vertientes y fuerzas que se manifestaron durante esos agitados y violentos años de disputa por el poder en la construcción del nuevo Estado mexicano.

Los estudios historiográficos regionales cada vez dan mayor cuenta de las experiencias femeninas en el ámbito de lo público al despuntar el siglo, visibilizando no sólo sus ejercicios de participación, sino también los contextos en los que gestaron sus demandas y organizaciones, así como las alianzas que permitieron su inserción posterior en los espacios de la política formal (Fernández, 2014; Fernández, Ramos y Porter, 2006; Lau, 2006). En este marco temporal y problemático, pero centrado en el espacio del otrora distante y aislado estado de Sonora, se coloca el interés del presente trabajo: reflexionar sobre la participación política que emprendieron algunas sonorenses al irrumpir en la arena pública durante los conflictos que conmocionaron al estado en ese periodo, 
hasta llegar a ocupar cargos administrativos, sindicales y partidarios, así como de elección popular una vez que se estableció el derecho al sufragio en $1953 .{ }^{1}$ Las reflexiones que en este artículo se presentan, son producto de un trabajo de archivo que se realiza desde hace algunos años para documentar la presencia y participación activa de las mujeres en los procesos políticos que se vivieron en Sonora durante los convulsos tiempos de la posrevolución, y pretenden contribuir a los estudios de género sobre las mujeres en la historia regional.

\section{LOS ESPACIOS DE LA PARTICIPACIÓN}

La educación y el trabajo remunerado han sido, para las mujeres, condiciones primordiales para desplegar procesos de emancipación de su condición de género. Lo son todavía en los tiempos que corren, y lo fueron con mayor fuerza en las primeras décadas del siglo xx (Cano, 1991, 1996; François, 2015; Goldsmith, 2006; Hernández, 2015; Porter, 2006, 2015; Robles, 2015). No es de extrañar, por ello, que en los años treinta, 40 y 50 fueran las maestras y las trabajadoras sindicalizadas las mujeres que se visibilizaron públicamente en Sonora, ya sea dirigiendo una protesta, un movimiento social o encabezando una organización. El magisterio y las asociaciones sindicales destacaron en tanto plataformas preferentes desde las cuales las sonorenses irrumpieron en la escena pública.

Las sonorenses comenzaron a acceder a la educación de forma más amplia desde la Ley de Instrucción Pública de 1881. La ley establecía la obligatoriedad de los padres de enviar a la escuela a sus hijos, hijas y descendientes bajo su patria potestad desde que cumplían cinco años (Bustamante, 1998). Los gobiernos preconstitucionales, tanto como los que les siguieron también priorizaron la educación, abriendo escuelas en todo el estado y facilitando la educación de las mujeres.

Desde los años veinte y treinta, las maestras y las sindicalistas estuvieron presentes en los conflictos que conmocionaron a Sonora. De igual forma

${ }^{1}$ No se pretende realizar una biografía de las mujeres seleccionadas para este trabajo, tampoco comparar o contrastar sus experiencias con las que otras realizaron en distintas entidades del país. Por lo demás, hacerlo requeriría poseer una información de archivo con la que no se cuenta en estos momentos. Lo que interesa es ofrecer algunas pinceladas de su actuar y recuperar sus experiencias de participación en los procesos políticos del momento histórico que les tocó vivir, para posicionarlas en la historiografía regional. 
abrieron espacios en la prensa para exponer sus opiniones sobre los asuntos que agitaban al estado o se involucraron en las filas de los órganos partidarios locales y en las candidaturas de quienes competían por el gobierno estatal (Cejudo Ramos, 2013, 2019; Zúñiga Elizalde, 2018, 2020).

Sin concederles derechos de ciudadanía, los distintos gobiernos que encabezaron la entidad en los años de la posrevolución estimularon la participación y organización de las mujeres, pero dentro de los cauces de sus proyectos políticos de gobierno. De manera más clara lo hicieron Rodolfo Elías Calles Chacón (1931-1934) y Ramón Yocupicio (1937-1939). Para Vaughan (2001, p. 100), el primero no sólo incorporó a las(os) maestras(os) "en la construcción de la maquinaria del PNR [Partido Nacional Revolucionario] estatal", sino que auspició financieramente "la preparación radical" de unos y otras para propulsar sus planes económicos de reconstrucción comunitaria. En palabras de Vaughan (2001): "El proyecto de la reconstrucción comunitaria contó con una abundancia de mujeres, quienes eran la mayoría entre los maestros federales. Los altos índices de alfabetización femenina facilitaron la movilización de las mujeres. Fueron maestras quienes organizaron a madres $y$ adolescentes en sociedades de madres y clubes de señoritas" (p. 106).

Yocupicio, por su parte, una vez que asumió la gubernatura en 1937 impulsó la creación de la Confederación de Trabajadores de Sonora (cTs) y la adhesión masiva de los sindicatos, entre ellos los del magisterio, compitiendo de manera denodada con la naciente Confederación de Trabajadores de México (стм) (Almada, 2009; Enríquez, 1987).

La organización de las trabajadoras en sindicatos se da desde la década de los veinte, y tuvo un auge inusitado en los años treinta, luego de la promulgación de la Ley Federal del Trabajo en 1931. Tanto Elías Calles Chacón como Ramón Yocupicio fomentaron el sindicalismo y la agrupación de los sindicatos en federaciones o centrales estatales. Para las(os) trabajadoras(es), los sindicatos se convirtieron no sólo en un medio para el avance de sus derechos laborales, sino que fueron plataformas políticas desde donde participaron y se posicionaron en la contienda pública. Para las mujeres fue un lugar fundamental para la formación política y la construcción de habilidades para el debate, la negociación y la toma de decisiones (Enríquez, 1987; Zúñiga, 2020; Zúñiga, Cejudo y Acedo, 2014). Precisamente fueron las sindicalistas, maestras como trabajadoras de oficios varios, las que encabezaron protestas y se posicionaron frente a los líderes políticos del momento para reclamar derechos, entre ellos el del voto (Zúñiga, Cejudo Ramos y Acedo, 2013). 


\section{ENTRE LA TRASGRESIÓN Y LA OBEDIENCIA: AVATARES DE CINCO MUJERES EN LA POLÍTICA ESTATAL}

A pesar de la pobre documentación de archivo que se preserva sobre la actuación pública de las mujeres en Sonora, es posible bosquejar la presencia activa de algunas de ellas en los distintos lados de las contiendas que derivaron de las luchas por el poder en el estado y de los diferentes proyectos políticos que pretendían implantarse. ${ }^{2}$ Algunas aparecen de manera episódica en algún acontecimiento, para luego desaparecer sin dejar huellas visibles. A otras las descubrimos de forma más continua en el tiempo, ya sea participando en una protesta, escribiendo en la prensa o dirigiendo una escuela o un sindicato. La acción pública de estas mujeres a lo largo de varias décadas nos revela un liderazgo femenino construido a contracorriente, en un mundo dominado por el poder masculino en todos sus espectros, en donde el avance de una pulgada en sus derechos se alcanzaba con grandes esfuerzos y sin garantías de no retroceso.

De estas mujeres aquí se reflexionará sobre los trazos que recorrieron cinco de ellas. No fueron las únicas, pero sobresalen porque su presencia fue más visible y permanente en el tiempo al ocupar en diferentes momentos cargos de importancia que las posicionaron rápidamente en el escenario público, en un juego de alianzas significativas con políticos y gobernantes de distinto cuño. Tres de ellas se educaron como maestras: Enriqueta Montaño Peralta de Parodi, ${ }^{3}$ Catalina Acosta de Bernal y Dolores Enedina Cuiltre Escalante. Las dos primeras pronto abandonaron la enseñanza para incorporarse en

${ }^{2}$ Entre otros conflictos que dividieron al estado en los años veinte y treinta se encuentran la revuelta de Adolfo de la Huerta, las movilizaciones a favor de la candidatura de José Vasconcelos, las campañas antichinos, la desfanatizadora y la que combatía la producción, venta y consumo de alcohol; la persecución religiosa y la llamada educación socialista que impulsó Elías Calles Chacón, además de las contiendas que se libraron entre las centrales obreras para apoderarse de la titularidad de los sindicatos que de manera amplia se creaban en todo el estado, así como las disputas por el poder que devinieron entre los seguidores de Plutarco Elías Calles y Álvaro Obregón tras el asesinato de este y la llegada posterior de Lázaro Cárdenas a la presidencia de la república. Para conocer al respecto, consúltese, entre otros, Almada (1998, 2009); Moncada (1988); Reñique (2003); Trueba (1990). Para analizar la participación particular de las mujeres en ellos, consúltese Cejudo (2019); Zúñiga (2018, 2020).

${ }^{3}$ Enriqueta se divorció de su marido pero siempre conservó su apellido. Más que por sus apellidos de soltera, se le conoce por el que tomó del marido: Enriqueta de Parodi. En este artículo así la llamaremos. 
puestos administrativos en el gobierno estatal, empleos que supieron combinar con la escritura y otras actividades que les ganaron presencia como formadoras de opinión en la prensa y la radio. La tercera dedicó su vida a la enseñanza y a la brega del sindicalismo magisterial. Su profesión, prestigiosa en aquellos años, les permitió a las tres enriquecer saberes y talentos; gracias a ellos pudieron establecer una red de relaciones convenientes con distintos personajes que las alejó de sus orígenes modestos para ser reconocidas con el paso del tiempo como mujeres modernas e instruidas.

Los puntos de partida de María Jesús Guirado Ibarra y Francisca Córdova Macalpin fueron diferentes, aunque sus orígenes, al menos en términos económicos, no fueron muy distantes de los que emanaron las maestras. Guirado y Córdova se insertaron desde jóvenes como trabajadoras asalariadas en la costura y desde ahí labraron su porvenir laboral y político. A pesar del bagaje cultural y educativo dispar de las cinco, todas tuvieron una presencia singular en momentos clave de definición del rumbo político que tomaba el Estado mexicano y su encarnación en el gobierno estatal. Cada una en sus ámbitos de inserción fue partícipe de la algarada femenina que se experimentó a partir de los años veinte, con sus momentos de expansión en los treinta, así como de los procesos de corporativización institucional de las organizaciones sociales y sindicales que se fueron dando durante los años posteriores. Su devenir estuvo signado por las alianzas que entablaron con los poderes locales y federales y las que cultivaron entre sí, aunque no siempre como pares.

\section{Enriqueta de Parodi}

Nació en Cumpas el 10 de marzo de 1897. En 1918 se casó con Alfredo Parodi Santoyos, de quien se divorcia posteriormente; de este matrimonio tuvo cinco hijos. En 1917 inició su actividad laboral como maestra en los pueblos de Tepache y Nacozari. Cejudo (2008a) señala que Parodi "es recordada como una escritora exitosa", aunque advierte que también debería serlo como periodista, en vista de que durante más de 50 años publicó artículos de opinión en la prensa, en los diarios El Pueblo y El Tiempo en Sonora, ${ }^{4}$ donde tuvo

${ }^{4}$ El Tiempo fue fundado en 1932 gracias al financiamiento del gobernador Rodolfo Elías Calles, y se publicó durante cuatro años. El Pueblo se creó en 1924 y desapareció en 1972. Para Cejudo (2013), este diario fue pionero del periodismo independiente. Las colaboraciones de 
un papel protagónico en la conformación de la opinión pública local, tarea nada fácil para una mujer de la época (Cejudo, 2008b).

Formó parte del primer Comité Central Ejecutivo de la Confederación Proletaria Nacional, ocupando la cartera de Acción Femenil. La organización se constituyó el 27 de febrero de 1942 y Parodi fue la única mujer que integró la dirigencia nacional. ${ }^{5}$ Su carrera se forja y promueve de la mano de los gobiernos posrevolucionarios, particularmente de Abelardo L. Rodríguez, presidente interino de la república de 1932 a 1934 y gobernador de Sonora de 1943 a 1948. La admiración de Parodi por este empresario y político sonorense fue tan grande, y su amistad tan estrecha, que la motivaron a escribir un pequeño relato biográfico sobre él, que tituló Abelardo L. Rodríguez, un devoto de la educación. Fue su colaboradora en el gobierno estatal a cargo de las Misiones Sonorenses de Superación Popular, en la dirección del Departamento de Organización Social y Cultural (Aragón, 2003b, p. 85). Fue promotora del arte, la educación y las letras, fundó bibliotecas y escuelas en todo el estado y participó en la creación de instancias y fundaciones para otorgar becas a estudiantes.

Se mantuvo en el mismo puesto durante varias administraciones. El gobernador Ignacio Soto (1949-1955), al terminar su mandato le agradece a su "estimada amiga" la "eficaz colaboración prestada a su Gobierno". ${ }^{6}$ Parodi fue diputada local por el PRI de 1967 a 1970 durante el gobierno de Faustino Félix Serna y falleció en Hermosillo el 18 de junio de 1978. Dejó una variada obra literaria y ese quehacer en el mundo de las letras le permitió insertarse y ocupar un lugar privilegiado en el escenario político, tanto estatal como nacional.

Sus escritos en la prensa en los años más álgidos de la campaña desfanatizadora ilustran muy bien sus convicciones políticas y su sentido crítico, también su postura sobre el lugar que ocupaban las mujeres en la sociedad. En ellos cuestiona a las maestras que renunciaron a sus empleos tras reivindicar su fe católica y su rechazo a los principios de la educación socialista emprendida por el gobernador Elías Calles Chacón. Pone en duda la autonomía de criterio de estas maestras al dejarse llevar por el consejo de curas

Parodi se extendieron también a periódicos y revistas en México y en el extranjero. Fue integrante del equipo editor del El Nacional, en la ciudad de México, y de El Informador, en Guadalajara, Jalisco.

${ }^{5}$ Fondo Oficialía Mayor. Exp. 234.4 "42" /15, 17 de marzo de 1942. Archivo General del Estado de Sonora (en adelante AgEs), México.

${ }^{6}$ Fondo Oficialía Mayor. Tomo 1597, exp. 06”45/4, julio de 1955. AGES, México. 
y sacerdotes (Cejudo, 2019, pp. 231-232). El feminismo de Parodi se ubica en el de muchas mujeres ilustradas del México de entonces, que reivindicaban derechos para las mujeres pero aceptando un esencialismo femenino como madres y cuidadoras. El 8 de septiembre de 1936, escribió: "[La mujer] no debe olvidar que antes que alcaldesa justiciera, que antes que diputada consciente, está su deber de ser buena madre. No la madre esclava de todos los convencionalismos de un siglo que ya pasó [...], sino la madre consciente que haga germinar en el alma y el pensamiento de sus hijos, la verdadera semilla libertaria que les expedite el camino por la vida en el futuro".

Y continúa: La mujer "en lugar de ahondar el distanciamiento que se inicia con esta pugna social debe de procurar tender el puente de la transigencia entre el hombre que le niega todo el derecho y ella que todo lo pide en igualdad”. Desde su perspectiva, las mujeres tenían que educarse sólidamente para que, en el futuro, cuando el hombre por fin se diera cuenta de esa preparación efectiva, no tendría "más remedio que aceptar nuestra participación en la marcha de los asuntos privados y públicos". ${ }^{7}$

\section{Catalina Acosta de Bernal}

Acosta de Bernal tuvo un recorrido similar al de Enriqueta de Parodi, con sus particularidades. Cejudo $(2009,2019)$ es quien mejor bosqueja algunos de sus trazos como escritora, profesora, funcionaria y locutora. Nació en Hermosillo y en 1915 inició sus estudios en la Escuela Normal; al egresar se incorpora rápidamente a la enseñanza. Como mujer de letras, escribió también en la prensa local y participó en la recién creada radio de Hermosillo (Cejudo, 2009). ${ }^{8}$

En 1930 el gobierno federal creó la primera escuela secundaria en la entidad, en la ciudad de Nogales. En 1937 se abrieron cuatro más, en Magdalena, Ciudad Obregón, Guaymas y Agua Prieta, pero "ya independientes [de la Federación] y con Plan de Estudios propios”, asegura Aragón (2003a, p. 75).

7 "Cooperación y no distanciamiento", El Tiempo, citado en Cejudo (2019, p. 224).

${ }^{8}$ Según Héctor Rodríguez Espinoza, la primera radio en Hermosillo (XEBH) se creó en 1935. Comenzó a transmitir el 20 de noviembre de ese año, de las 20:00 a las 24:00 horas, a través de la frecuencia $900 \mathrm{Kcs}$. Las estaciones que en ese año se sintonizaban en Hermosillo eran la XEHF de Nogales, y algunas de Estados Unidos y de Cuba. Publicado originalmente el 22 de enero de 2013. Recuperado de https://www.dossierpolitico.com/vernoticiasanteriores. php?artid=122883\&relacion $=$ dossierpolitico\& criterio 
La dirección de la de Agua Prieta quedó a cargo de Acosta de Bernal. Laboró en la Secretaría de Educación estatal entre 1937 y 1951, encabezando, entre otras responsabilidades, el Sistema Estatal de Escuelas Secundarias (Cejudo, 2009).

Tuvo un papel ambiguo respecto de la actuación del magisterio durante la campaña desfanatizadora de Elías Calles Chacón y de la educación denominada "socialista" que se pretendió impulsar en su gobierno. Poco después de la expulsión del callismo del estado y del país, se deslinda públicamente de aquel. El 12 de febrero de 1937 participa como ponente en el Congreso de Unificación Magisterial, celebrado en Querétaro. En la ponencia aborda los retos y dilemas que enfrentan las escuelas sonorenses y asegura que en los años previos no se realizó la educación socialista, puesto que el profesorado se concretó a fomentar la escuela desfanatizante, "que no era necesaria" dado que la "famosa desfanatización callista solamente vino a afirmar con gravados caracteres el fervor religioso", mientras cada casa se convertía en un templo y cada individuo en un creyente. Y sigue: "si nosotros luchamos por arrebatar los intereses del pueblo que son los intereses de la revolución de hecho realizábamos una escuela contrarrevolucionaria". Puntualiza que "los maestros (no reclutas) hemos visto soportando con resignación una cruel super estructura, que por una parte el gobierno nos extorsiona con represalias, ceses, destierros, encarcelamiento, cambios de gradaciones, etc., por otro lado la sociedad que nos desprecia y nos veja". ${ }^{9}$

No faltó quien objetara la radical crítica de Acosta a la política callista y su postura aparentemente cambiante: quema santos en su momento y cuestionadora de la desfanatización una vez caído el callismo. Lo interesante del posicionamiento público de la maestra es que exhibe cómo las mujeres podían definir sus propias estrategias de actuación en los distintos contextos que se iban conformando, adaptándose a los vaivenes políticos del momento. Como lo afirma Vaughan (2001), al igual que los líderes varones del magisterio y del sindicalismo, las mujeres supieron trasladar sus lealtades del callismo al cardenismo manteniendo "sus propias agendas radicales" (p. 123).

Con todo, el feminismo de Acosta no se aleja mucho de la perspectiva de Enriqueta de Parodi, como se observa en el artículo que publicó el 22 de septiembre de 1936:

9 "Toda nuestra oposición a la labor desfanatizante del profesorado fue justificada en el C. Magisterial”, El Pueblo, 18 de febrero de 1937, citado en Cejudo (2019, p. 233). 
Es necesario poseer un espíritu mediocre y contradictorio para negar a la mujer el importante papel que en todas las épocas ha desempeñado en la realización de las conquistas, y es necesario también estar dispuesto a obstaculizar su elevación cultural, como presta medida de amenazadora competencia en todas las actividades. Todavía en nuestros tiempos, hay quien argumente que una mujer preparada para la lucha ha perdido por eso su feminidad y yo declaro: Se es más femenina cuanto más culta se es. Se puede ser digna ama de casa, amorosa madre a la vez que culta escritora, dinámica empresaria, talentosa legisladora u obrera activa. ${ }^{10}$

Catalina Acosta de Bernal fue un buen exponente de ese ideal de mujer tan proferido para defender la presencia de las mujeres en el espacio público sin menoscabar su feminidad. Su crítica al carácter desfanatizante del sistema educativo de aquellos años se inscribe en el de muchas otras maestras que apoyaron al callismo, pero, una vez caído este, supieron reencauzar su activismo estableciendo nuevas alianzas con los nuevos poderes constituidos. Con todo, al igual que Parodi, y por encima de todo, se le reconoce por su legado literario. En tres palabras resume el periodista Abelardo Casanova la escritura de Acosta: expresiva, vehemente y arrolladora (Cejudo, 2009).

\section{Dolores Enedina Cuiltre Escalante}

Poco se conoce hasta ahora de la larga trayectoria laboral y el posicionamiento político de la maestra Dolores Enedina Cuiltre Escalante, a quien se logra identificar desde los años treinta hasta los ochenta. ${ }^{11}$ En 1935 se le ubica como directora de la Escuela Primaria Federal de Masiaca, municipio de Navojoa. En la cresta de la persecución religiosa, junto con otros integrantes del comité de educación de la localidad, solicita al gobernador sustituto Emiliano Core$1 l a^{12}$ el edificio que se utilizaba como templo católico, para instalar ahí la ofi-

${ }^{10}$ El Pueblo, citado en Cejudo (2009).

${ }^{11}$ Presuntamente nació en Navojoa, aunque por lo pronto se desconoce su fecha de nacimiento.

${ }^{12}$ Corella sustituye a Rodolfo Elías Calles Chacón en la jefatura de gobierno, cuando este la deja en 1934 para ocupar la Secretaría de Comunicaciones y Obras en el gobierno presidencial de Lázaro Cárdenas. Tras la expulsión del grupo callista en 1935, se desconocen los poderes en Sonora y Corella abandona el gobierno. 
cina de correos y la comisaría de policía. El gobernador se lo concede..$^{13} \mathrm{Al}$ año siguiente, Cuiltre fue integrante y fundadora de la Unión Sindical de Maestros Socialistas de Navojoa. ${ }^{14}$

Cuando se crea la primera escuela secundaria en Navojoa en 1940, Cuiltre se integra a la planta docente como maestra de español y geografía; fue la única mujer que impartió cursos básicos, puesto que otras dos maestras incluidas lo eran de taquigrafía y economía doméstica, a cargo de Aurora Salazar de Torres y Amalia de Ceceña, respectivamente. En la ceremonia de apertura de la secundaria estuvo presente la maestra Catalina Acosta de Bernal, en ese entonces jefa de la Sección de Secundarias Estatales en Sonora (Zatarain, 24 de diciembre de 2011).

El sindicalismo magisterial de la región del Mayo del que formaba parte Cuiltre, mantuvo una postura ambivalente respecto de las políticas gubernamentales en turno: por un lado, se disciplinaba a los dictados del corporativismo y, por otro, protestaba si estos afectaban sus derechos laborales o el monto de sus salarios. En 1938 Cuiltre ocupaba la Secretaría de Acción Femenil del Sindicato Regional de Navojoa, sección de la Federación de Maestros Socialistas de Sonora (fMSs), creada bajo el auspicio de Ramón Yocupicio. La recaudación de fondos que se dio en ese año durante la Campaña Pro-Redención Nacional para cubrir la deuda por la nacionalización del petróleo, generó muchas controversias entre los sindicatos, pues sobre ellos se impusieron altas cuotas que tenían que sufragar las(os) trabajadoras(es) con sus salarios. La directiva sindical de la que formaba parte Cuiltre fue una de las que se reveló, retando no sólo a la dirección de la Federación sino al mismo gobernador Yocupicio, asegurando que por decisión de asamblea la cuota sería voluntaria y de acuerdo con sus sueldos y necesidades económicas. ${ }^{15}$

Cuiltre tuvo una larga hoja de servicios como maestra en la Dirección General de Educación Pública del Estado. Fue maestra o directora ininterrumpidamente de diversas escuelas primarias y secundarias, principalmente en Navojoa, pero también en otras localidades; a mediados de los años cua-

\footnotetext{
${ }_{13}^{13}$ Fondo Cultos y Templos. Tomo 3, exp. 312.4/34, 22 de marzo de 1935. AGEs, México.

${ }^{14}$ Ahora, 21 junio de 1936.

${ }^{15}$ Fondo Oficialía Mayor. Archivo Interno. Caja 48, exp. 234.2 “38”/3, 3 de abril de 1938. AgEs, México.
} 
renta comienza a dar clases en colegios particulares y posteriormente crea su propio plantel, al que llama con su nombre. ${ }^{16}$

De una u otra forma se vio involucrada en el conflicto magisterial suscitado en 1960, cuando algunos sindicatos regionales abandonaron las filas de la Federación Estatal de Maestros Sonorenses (FEMS ${ }^{17}$ para ingresar al Sindicato Nacional de Trabajadores de la Educación (SNTE). El conflicto magisterial inicia en diciembre de 1959 en la sección núm. 4, de Hermosillo, motivada por la negativa de la Dirección de Educación, con la complacencia de la dirigencia sindical estatal, de otorgar aguinaldo y aumentar los salarios mínimos, entre otros recortes de prestaciones (López Romero, 2016). El periódico El Pueblo reseña ampliamente el conflicto, el que se amplía en 1960 e incorpora la destitución de los líderes sindicales. En la crónica que hace el 26 de enero se alaba la protesta y se reconoce la participación que en esta lucha están teniendo las maestras: "En esta se han significado las maestras desde que se inició la lucha. Ellas le han dado organización a su bando, han asumido la responsabilidad que quiera arrojarles la Dirección General y están dispuestas a defenderse contra cualquier acto de represalia de que se les quiera hacer víctimas. Tienen de su parte la justicia y el derecho" (citado en López Romero, 2016, p. 37).

La sección 4 de Hermosillo enarbola la protesta y la separación de la federación estatal. En marzo de 1960 deciden integrarse al SNTE para formar la sección 55 (López Romero, 2016).

El conflicto se alarga en el tiempo, pues detrás de él se encuentran las distintas vertientes de los grupos políticos que rivalizan por el poder, entre los de la federación y los del gobierno estatal. El 7 de diciembre de 1961, la Federación Estatal de Maestros de Sonora le escribe a Alicia Arellano Tapia, ${ }^{18}$ diputada por Sonora del Congreso de la Unión, para que intervenga ante el presidente Adolfo López Mateos, a fin de resolver el problema magisterial. Firman la carta el comité directivo de la Federación, entre ellos las profesoras Evangelina Paredes, secretaria de Finanzas, y Dolores Enedina Cuiltre, secre-

${ }^{16}$ Fondo Educación. Archivo Interno. Caja 14, exp. 111.1-71/30125, 30 de abril de 1965. AGEs, México.

${ }^{17}$ La FEMs fue creada en 1937 por el gobernador Román Yocupicio, a fin de impedir la afiliación del profesorado a la Federación Estatal Socialista de Trabajadores del Estado, de filiación lombardista. La FEMs estaba conformada por 21 sindicatos regionales (Escobosa, 1995).

${ }^{18}$ Madre de la gobernadora de Sonora Claudia Pavlovich Arellano, durante el periodo 2015-2021. 
taria de Acción Femenil. Marcan copia al gobernador Luis Encinas y a los 21 sindicatos regionales adheridos a la FEMs. ${ }^{19}$

Queda por indagar el desenlace que tuvo la solicitud, lo cierto es que para Cuiltre resultó en un despido de la Dirección de Educación unos años después. Mediante el oficio 71-3135, la institución le comunica la baja "como profesora de planta, comisionada Directora de su propio plantel en Navojoa (Colegio Cuiltre) por hacer caso omiso a las disposiciones, leyes y reglamentos que regulan la actividad educativa, suspendiendo labores por una semana en apoyo a huelga". ${ }^{20}$ Para ese entonces ella seguía formando parte del Sindicato Regional de Maestros Núm.1 de la FEMs, en Navojoa. ${ }^{21}$

Pese a todo, ella continuó su labor como educadora, lo que le valió con los años un importante prestigio en la localidad. La invitación que le hacen en 1977 para que esté presente en el acto de fundación del Instituto Tecnológico de Sonora (ITSON) en Navojoa, es una muestra de ello (Estrella, 2015). Años después, de 1981 a 1985, se le ubica como directora del plantel Álamos de lo que ahora es El Colegio de Bachilleres (Valdez, 2008). Mucho queda por indagar sobre la actuación pública de Enedina Cuiltre como profesora y sindicalista; también sobre su posicionamiento frente al conflicto magisterial y la relación que mantuvo con otras mujeres destacadas, como Enriqueta de Parodi y Catalina Acosta, y con los grupos de poder que contendían en la región, así como con María Jesús Guirado, líder indiscutible en Navojoa donde Cuiltre construyó también su quehacer laboral y sindical.

\section{María Jesús Guirado Ibarra}

Guirado es conocida por ser la primera mujer en ocupar una curul en el Congreso local en 1955, luego de que se promulgara en 1953 el derecho al sufragio para que las mujeres pudieran votar y ser votadas. ${ }^{22}$ Nació en Álamos y desde temprana edad se insertó a laboral asalariadamente. Al despuntar los años treinta se dedica ya a la costura. En sus inicios como sindicalista, hay quien

\footnotetext{
19 Fondo Educación. Archivo Interno. Caja 14, 7 de diciembre de 1961. AGEs, México.

20 Fondo Educación. Archivo Interno. Caja 14, exp. s/n, 2 de junio de 1967. AgEs, México.

${ }^{21}$ Fondo Educación. Archivo Interno. Caja 14, 30 de agosto de 1965. AGEs, México.

22 En Sonora la Constitución estatal se reformó en 1954.
} 
la identifica vinculada a la izquierda lombardista, ${ }^{23}$ aunque falta documentar con claridad esa relación. Lo cierto es que en su larga trayectoria supo establecer fuertes lazos políticos y alianzas convenientes con los distintos políticos y grupos de poder que rigieron el estado en esos años, gracias al sólido liderazgo que construyó en y desde el Sindicato Femenil de Costureras de Navojoa.

Para 1937 Guirado se encuentra ya inmersa en la vida de las asociaciones sindicales. Está presente, como parte de su sindicato, junto a sus compañeras Josefa P. vda. de Arce, Justina Regalado y María del Rosario Leyva, en la fundación de la Federación Obrero Campesino del Distrito de Álamos, resultado del trabajo de organización que la recién creada Confederación de Trabajadores de Sonora (CTS) estaba realizando en el sur del estado. ${ }^{24}$

Como las maestras, las trabajadoras sindicalizadas también se fueron acoplando a los vaivenes políticos de la época. Más allá de sus propios pareceres, condescendían o se adherían tácitamente a las políticas marcadas por el gobernante en turno, y luego se reconducían dependiendo de la dirección que tomaba el viento. En el mejor de los casos mantenían una cierta distancia sin confrontarse con los poderes imperantes. Sin derechos ciudadanos y en relaciones de fuerza desventajosas, las sindicalistas labraron sus liderazgos con astucias y destrezas, urdiendo estrategias diversas para avanzar en sus posicionamientos. Así podemos entender que en los tiempos de la campaña desfanatizadora, el Sindicato Femenil de Costureras de Navojoa haya ocupado, junto con otros sindicatos, un templo católico y la casa cural en la localidad, y que, una vez pasado el momento de la persecución, se apresuraran a desalojarlos. ${ }^{25}$

Guirado no fue la única costurera del sindicato femenil que construyera un protagonismo en la región del Mayo. Hubo otras mujeres, entre ellas Esther Padilla, quien fue su suplente en la diputación que tuvo en 1955. La diferencia estriba en que el liderazgo de María Jesús tuvo una trascendencia mayor, tanto temporal como espacial. Pronto, todavía en los años treinta, las

${ }^{23}$ Bulmaro Pacheco, 15 de marzo de 2016. Recuperado de http://www.casadelasideas. com/recientes/de-mujeres-y-derechos/

${ }^{24}$ El Mayo, 5 de agosto de 1937.

${ }^{25}$ El 1 de junio de 1937, la Secretaría General del sindicato le informa al gobernador Yocupicio, mediante una carta, que entregaron las instalaciones a la junta vecinal. En una carta anterior, del 26 de mayo, afirman que no están ocupando ni necesitan el local donde vivía el cura. Entre las firmas de las cartas se encuentra la de María Jesús Guirado. Fondo Cultos y Templos. Tomo 3, exps. 312.6/4 y 312.6/4. AgEs, México. 
autoridades laborales le solicitaban su intervención para dirimir conflictos gremiales e intergremiales en la región. ${ }^{26}$

El Sindicato Femenil de Costureras de Navojoa se consolidó fuertemente durante los años cuarenta y principios de los cincuenta, con confrontaciones frecuentes con la empresa Bengala, S. A., para la que trabajaban, propiedad de Agustín Bouvet. Si bien el Comité Ejecutivo del sindicato se renovaba cada año, era común encontrar los mismos nombres en uno u otro cargo, o repitiendo en el mismo pasados ciertos años; ese es el caso de Guirado y Padilla. Sin importar quién estuviera a la cabeza, la combatividad de las costureras resulta tangible al documentar las negociaciones que mantenían con la empresa para renovar anualmente el contrato colectivo. Un asunto de conflicto permanente fue el monto de las tarifas vigentes de sus trabajos de maquila para la empresa.

La correspondencia entre el sindicato y distintas autoridades, ya sea el gobernador, el secretario de Gobierno, el jefe del Departamento del Trabajo o el inspector laboral, era nutrida, también la que mantenían con la empresa y la dirigencia de la стs a la que las costureras estaban adheridas. En ella se explicitan los detalles de los conflictos y las peticiones de intervención institucional o sindical para resolverlos. Dependiendo de los asuntos que se trataran, también se giraban copias a distintos sindicatos de la región del Mayo o al sindicato de costureras de Hermosillo. Para determinados problemas o demandas, las cartas de petición eran firmadas también por otros sindicatos, lo que revela la fuerza política que ejercía el femenil de Navojoa en el sindicalismo de la región. ${ }^{27}$

Esta correspondencia se mantuvo durante los gobiernos de Anselmo Macías Valenzuela (1939-1943), Abelardo L. Rodríguez (1943-1948), Horacio Sobarzo Díaz (1948-1949) e Ignacio Soto (1949-1955). En un lenguaje formal, respetuoso de la autoridad, pero reivindicador de los derechos que les correspondían como trabajadoras, las cartas del sindicato informaban, solicitaban o agradecían a las autoridades sobre los asuntos a resolver o resueltos y sobre la necesidad de intervención gubernamental en los conflictos. Se puede decir que el Sindicato Femenil de Costureras y sus dirigentes, entre ellas María Jesús Guirado, se mantenían dentro de los lindes de los poderes instituciona-

${ }^{26}$ Fondo Oficialía Mayor. Archivo Interno. Caja 48, tomo s/n, exp. 234.3. 38”/3, 17 de marzo de 1938. Ages, México.

${ }^{27}$ Fondo Oficialía Mayor. Tomo 1610, exp. 234.3 “45/15, 10 y 17 de mayo de 1945; 30 de abril de 1946; 1 de octubre de 1949; exp. 234.5 “45/15, 27 de marzo de 1947; tomo 1723, exp. 234.4 “47/31, 13 de marzo de 1951. Ages, México. 
lizados, pero guardando un cierto margen para el juego de fuerzas y el disenso respecto de las políticas y decisiones tomadas por las dirigencias de la CTS.

A lo largo de su existencia, la Confederación de Trabajadores de Sonora (ст) presentó a su interior diversas luchas por el poder y confrontaciones entre personajes que buscaban posicionarse en la dirigencia y en el favor del gobernante en turno. Las costureras de Navojoa supieron navegar en esas contiendas sin menoscabo de su fuerza como sindicato. ${ }^{28}$ Por el contrario, mostraron un gran dinamismo en sus gestiones y una gran iniciativa y determinación para actuar directamente, sin intermediarios, en los asuntos que les competían. La documentación de archivo devela un abundante intercambio de cartas, dirigidas a distintas personalidades e instancias, con peticiones diversas, todas ellas enfocadas en el fortalecimiento de sus capacidades de negociación y en la mejora de las condiciones en las que realizaban su trabajo. En esa correspondencia se observa el desarrollo de ciertos liderazgos femeninos y la fuerza de interlocución que estaba cobrando el sindicato femenil frente a los distintos poderes estatales. ${ }^{29}$

A principios de los años cincuenta, la inclusión de Guirado en la directiva del sindicato era más bien simbólica que operativa. Se mantuvo en la comisión de justicia por varios años, y firmaba peticiones con la secretaria general en turno, queriendo con ello, posiblemente, darle mayor fuerza y legitimidad a las demandas expuestas sin involucrarse directamente en las tareas cotidianas que las demás dirigentes estaban obligadas a realizar. El liderazgo y la capacidad de interlocución de Guirado respecto de los distintos agentes que intervienen en todo conflicto laboral se mostró de manera contundente en repetidas ocasiones, entablando comunicación directa con el gobernador en turno sin necesidad de ostentar un cargo sindical. ${ }^{30}$

En 1953, el sindicato se disuelve y sus integrantes se constituyen en cooperativa, a la que llaman Sociedad Cooperativa Industrial de Producción, Rosa Durazo de Soto, S. C. L., es decir, el nombre de la esposa del gobernador Ignacio Soto. La cooperativa contó con el apoyo financiero del gobierno esta-

${ }^{28}$ Fondo Oficialía Mayor. Tomo 1610, exp. 234.3 “45/15, 21 de enero, 3 de junio y 1 de julio de 1948. ages, México.

${ }^{29}$ Fondo Oficialía Mayor. Tomo 1610, exp. 234.3 "45/15, 1 de octubre de 1949. AGEs, México.

${ }^{30}$ Fondo Gobernación. Tomo 1610, exp. 234.3 “45”/15, 7 de febrero de 1915; tomo 1723, exp. 234.4 " 47/31, 26 de noviembre de 1952; tomo 1892, exp. 234.6/2, 23 de junio de 1953; exp. 234.6 “50/5, 19 de julio de 1953. AGEs, México. 
tal, el cual las dirigentes del otrora sindicato femenil no dejaron de agradecer. ${ }^{31}$ Para ese año, María Jesús Guirado era la administradora del Centro de Capacitación Femenil en Navojoa. ${ }^{32}$ Como tal se dirige a las administradoras de los demás centros de capacitación para mujeres en el estado, exhortándolas para que escriban al gobernador Ignacio Soto "rindiéndole un voto de simpatía". Agrega que han constatado los beneficios que Soto está haciendo en la entidad, por lo cual "no podemos menos que reconocer sus buenas obras realizadas material y espiritualmente en beneficio de las hijas de Sonora”. Marca copia a la profesora Enriqueta de Parodi, ${ }^{33}$ jefa del Departamento Social y Cultural en el Estado. ${ }^{34}$

El apoyo de Guirado al gobernador fue uno más en la avalancha de declaraciones de los sindicatos a favor de Soto. Para estas fechas, la maquinaria del corporativismo estaba ya bien engrasada. En tanto, las costureras convertidas en cooperativistas continúan en 1954 solicitando y recibiendo ayuda económica del gobierno para ampliar sus instalaciones y fortalecer su organización. Esther Padilla se mantiene como presidenta del Consejo de Administración ${ }^{35}$, y se prepara para los nuevos derroteros que se aproximan.

En 1955, María Jesús Guirado es electa diputada local por el PRI, tras la reforma electoral que posibilita a las mujeres participar en una contienda electoral. Esther Padilla ostenta la suplencia. Para entonces, los vínculos con los hombres del poder eran muy fuertes. Cuando Ignacio Soto concluye su

${ }^{31}$ Fondo Oficialía Mayor. Tomo 1892, exp. 234.6/2, 23 de junio de 1953; exp. 234.6 “50/5, 19 de julio de 1953 y 2 de febrero de 1954. AgEs, México.

${ }^{32}$ Desde su primer informe de gobierno, Ignacio Soto manifiesta el interés por crear los centros de capación para mujeres. A lo largo de su mandato se abrieron seis centros, en distintas ciudades del estado. Los centros se enfocaron en impartir "conocimientos prácticos para administrar el hogar o bien para ganarse la vida cuando por circunstancias adversas se vieren obligadas [las mujeres] a ser el sostén de su casa". Los cursos fueron de corte y confección, costura y cocina práctica, repostería, conservación de frutas y legumbres, tejido y bordado. Informe de Gobierno de Ignacio Soto (1949-1955), rendido ante la XL Legislatura del Congreso local, donde Guirado era diputada propietaria en funciones. Fondo Oficialía Mayor. Tomo s/n, exp. 187 “50" /1, 31 de agosto de 1955. AGES, México.

${ }^{33}$ Los centros dependían del departamento que dirigía Parodi. Ella es quien recibía los recursos dispuestos por la Tesorería General del Estado, a fin de sufragar los gastos de renta de local o viajes de las administradoras para su capacitación. Fondo Oficialía Mayor. Exp. 331.25 "54" /3, 15 de febrero de 1954; 331.21 "54" / 5, 19 de febrero de 1954; exp. 331.21 “54"/6, 9 de octubre de 1954; 331.25 “54"/3, 28 y 29 de enero de 1955. AGEs, México.

${ }^{34}$ Fondo Gobernación. Tomo 1879, exp. 221. 1 “50/1, 26 de marzo de 1953. AGEs, México.

${ }^{35}$ Fondo Oficialía Mayor. Tomo 2090, caja 346, exp. 312.3 “54”/3, 2 de febrero de 1954. AGEs, México. 
mandato, escribe una carta de despedida a María Jesús. La llama "estimada y fina amiga", y agradece "la valiosa colaboración que prestó a su Gobierno". Sin duda mucho tenía que agradecerle. ${ }^{36}$

Guirado fue diputada local de 1955 a 1959. En esos años es nombrada secretaria general de la CTS, convirtiéndose también en la primera mujer en ocupar ese puesto. Como dirigenta sindical tuvo una activa gestión, al mismo tiempo que ejercía como diputada; en contacto directo con las instancias gubernamentales del trabajo, se involucró de lleno en los conflictos laborales de los sindicatos agremiados, como el que vivió el Sindicato de Molineros y Secadoras de Arroz del Valle del Yaqui. ${ }^{37}$

Mientras Guirado ejercía como diputada y dirigenta de la CTs, las costureras organizadas en la Cooperativa Industrial de Producción Rosa Durazo de Soto, daban el último viraje de rumbo a su agrupación. Las socias deciden disolver la sociedad; previo a ese paso, dan su conformidad para que se venda el terreno y el inmueble donde operaban como cooperativa y aceptan que lo adquiera el gobierno para la construcción de una escuela. Esther Padilla realiza todos los trámites para la venta. Para entonces, Álvaro Obregón Tapia (hijo del general) ocupaba la jefatura del gobierno estatal, ${ }^{38}$ con quien Guirado mantuvo un vínculo muy cercano.

\section{Francisca Córdova Macalpin}

Córdova es quizás la menos célebre de las cinco mujeres y en pocas ocasiones se le menciona si no es para señalar su militancia radical en las protestas contra la persecución religiosa y en el apoyo posterior que le dio a Ramón Yocupio en su campaña por la gubernatura. Pese a ello, o precisamente desde esa postura, se labró una sólida carrera política en las organizaciones aglutinadas en el PRM y el PRI, lo que le permitió ocupar la suplencia de una diputación federal también en 1955, por el distrito 2 de Sonora. ${ }^{39} \mathrm{La}$ información que se dispone, revela que antes de Guirado y Córdova sólo dos sonorenses

${ }^{36}$ Fondo Oficialía Mayor. Tomo 1597, exp. 06”45/4, 31 de agosto de 1955. AgEs, México.

${ }^{37}$ Fondo Oficialía Mayor. Tomo 1892, exp. 234.3 “50/15, 30 de enero de 1957. AgEs, México.

${ }^{38}$ Fondo Oficialía Mayor. Tomo 2090, caja 346, exp. 312.3 “54" /3, 13 de agosto de 1956; tomo 1892, exp. 312.3 "54" /3, 13 de agosto de 1956. AGEs, México.

${ }^{39}$ Lesislatura 43. http://www.diputados.gob.mx/sedia/biblio/virtual/dip/leg27-60/Legislatura_43.pdf 
ocuparon un cargo de índole electoral, en 1941, pero como regidoras; una en el Ayuntamiento de Huatabampo: Leonor Baldenegro, como regidora propietaria, ${ }^{40}$ y Esquipula López, como suplente en el ayuntamiento de Huépac. ${ }^{41}$

Al igual que Guirado, Francisca Córdova labró un tramo significativo de su carrera política dentro del sindicalismo de la cTs. Sin embargo, su historia resulta casi desconocida a pesar de toparnos con su nombre en protestas sociales o en cargos sindicales o partidarios, principalmente. Tal vez el protagonismo de Córdova, a diferencia del de Guirado, tuvo menos realce porque su trayectoria no la construyó en un solo sindicato, o porque el sindicato que dirigió no adquirió la solidez, fuerza y permanencia en el tiempo que logró el Femenil de Costureras de Navojoa. También puede ser, como veremos enseguida, que la parte más importante de su trayectoria política la hizo dentro de las agrupaciones partidarias del PRM, y después en el PRI.

Existen muchos vacíos por llenar en la larga trayectoria de esta interesante y controvertida mujer, que salta a la palestra pública en plena campaña desfanatizadora, tomando la calle para protestar por el cierre de los templos y la expulsión de los sacerdotes, para luego incursionar en el sindicalismo de la CTS y, después, en cargos políticos del partido en el poder. Para reconstruir con mayor detalle su historia política, y comprender la red de alianzas que fue tejiendo hasta llegar a 1955 y a la suplencia de una diputación, es necesario realizar en el futuro un arduo y cuidadoso trabajo de investigación de archivo. Su carrera tomó varios caminos; para rastrear sus pasos, es necesaria una indagación más laboriosa que la que aquí se presenta.

Se le identifica en plena confrontación social durante el gobierno de Rodolfo Elías Calles Chacón. Fue una de las activistas más firmes contra la persecución religiosa. En 1934 la policía de Hermosillo deja asentado en acta el reporte que hizo de los eventos suscitados en la plaza Zaragoza, donde se reunió un grupo numeroso de mujeres para exigir a las autoridades la entrega de las iglesias. El parte policiaco señala que, desde las tres de la tarde, las mujeres, en forma violenta, se aglomeraron en la plaza y "desordenada y amenazadoramente profirieron denuestos contras las autoridades municipales y del Gobierno del Estado”. Entre estas mujeres se señala a las maestras

40 Fondo Oficialía Mayor. Tomo 2, caja 115, exp. 221.5 “41” 2720, 3 de octubre de 1941. AGEs, México.

${ }^{41}$ Fondo Oficialía Mayor. Tomo 2, caja 115, exp. 221.5 “41” 2721, 6 de octubre de 1941. AGEs, México. 
Antonia Figueroa, Beatriz Beraud y María Luisa Aguilar. El informe señala que, por la noche, a las ocho horas, Francisca Córdova "encabezaba el grupo tumultuario de mujeres"; se precisa que estas enfrentaron a la policía llamándolos "perros", "desgraciados", "maniquís del gobernador" "mantenidos", entre otros improperios. ${ }^{42}$

En 1936, Francisca Córdova firma, junto con muchas otras mujeres, una carta dirigida al gobernador en turno, donde se pide restablecer el culto católico para reparar el daño causado a la sociedad. ${ }^{43}$ La carta va acompañada de 143 páginas de firmas de mujeres. ${ }^{44} \mathrm{Al}$ mismo tiempo que protesta, Córdova se encauza en la conformación de un nuevo sindicato femenino, se organiza con otras mujeres para apoyar la candidatura de Román Yocupicio a la gubernatura y colabora en la constitución de la стs una vez que el militar asume su cargo en 1937 (Cejudo, 2019; Zúñiga, 2020). ${ }^{45}$

Córdova desempeñó un papel central en la conformación de la CTs. En el evento de conformación que se celebró el 25 de mayo de 1937 en Hermosillo, Escobosa (1995) la nombra como uno de los personajes principales que estuvo en primera línea. Prontamente Córdova se incorporó al comité directivo de la Confederación, ocupando la Secretaría de Acción Femenil en 1938. En ese año dirigía el Sindicato de Actividades Domésticas y Similares de Hermosillo. Como su secretaria general, asiste como delegada a la convención donde se elegirán representantes ante la Junta de Conciliación y Arbitraje, para el periodo del 1 de enero de 1939 al 31 de diciembre de 1940. Asiste llevando la representación de 242 votos, lo que muestra que su sindicato tenía un buen número de agremiadas. ${ }^{46}$

${ }^{42}$ Fondo Cultos y Templos. Tomo 4, exp. 235/149, 4 de septiembre de 1934. AgEs, México.

${ }^{43}$ Sobre el conflicto religioso y la participación de las mujeres en las protestas contra la persecución religiosa, véase Cejudo (2019).

${ }^{44}$ Fondo Cultos y Templos. Tomo 6, exp. 312.6/589. Ages, México.

${ }^{45}$ Sobre el panorama sindical existente en esos años, Enríquez precisa que la cTs nació el 25 de mayo de 1937, y para junio de ese 1937 surge su opositora, la Federación de Trabajadores de Sonora, adherida a la стм. Esta agrupaba los sindicatos obreros y campesinos del sur de la entidad. La membresía de la cTs se centraba en Hermosillo, Nogales, Guaymas y Magdalena, concentrando a "los empleados de servicios (costureras, cocineras, meseras, domésticas, cargadores, músicos, choferes, etc.), artesanos (carpinteros, pintores, mecánicos, electricistas, plomeros, curtidores, etc.); agrupaban también a los Veteranos de la Revolución y algunas secciones de la Federación Estatal de Maestros Sonorenses socialistas (FEMSs) así como un gran número de sindicatos de oficios varios" (Enríquez, 1987, p. 92).

${ }^{46}$ Fondo Oficialía Mayor. Archivo Interno. Caja 48, exp. 234.0 “38”, 1 de noviembre de 1938. AgEs, México. 
En 1939, continúa en la directiva de la confederación. En poco tiempo construye un valioso protagonismo que le abrirá las puertas a la dirigencia de las instancias del partido en el poder. Documentos de archivo muestran la capacidad de intervención que tuvo como líder negociando conflictos gremiales e intergremiales, así como la autoridad política que asumía ante otras lideresas femeninas. ${ }^{47}$

No se cuenta con información sobre las actividades del Sindicato de Actividades Domésticas y Similares de Hermosillo al que perteneció Córdova. Si este se mantuvo en el tiempo o desapareció. Como haya sido, Córdova siguió avanzando en su carrera política. En 1941 aparece como secretaria de Actas y Acuerdos, para el periodo 1941-1942, del comité directivo de la recién creada Federación Obrero Campesina de Hermosillo. El organismo se adhiere a la Cтs y, posteriormente, una vez creada, a la Confederación Proletaria Nacional, de la que formó parte Enriqueta de Parodi como secretaria de Acción Femenil de la dirigencia nacional. Para el siguiente periodo, que comienza en 1942, Córdova se mantiene en la directiva de la federación, pero a la cabeza de la Secretaría de Acción Femenil. Repite en el comité en el siguiente periodo, el que se amplía a dos años, de agosto de 1943 a agosto de 1945, pero ahora en la cartera de Estadística y Finanzas. ${ }^{48}$

En ese periodo, el PRM tenía sus buenos años incorporando en sus programas de trabajo el propósito de incentivar la participación de las mujeres. Sin embargo, pocas estaban presentes en cargos importantes de las instancias donde se tomaban decisiones. Para la época, las mujeres cuando mucho ocupaban las carteras de acción femenil de las asociaciones mixtas. Ellas tenían mejores oportunidades de foguearse políticamente en las organizaciones exclusivas de mujeres, como bien lo analiza Hernández (2015) al estudiar a las obreras de Monterrey.

Córdova fue una pionera en el estado en adentrarse a los organismos partidarios y mantenerse en ellos hasta llegar a la reforma constitucional que promulgó en 1953 el derecho al sufragio para las mujeres. Y su oportunidad le llegó en 1943. A través de la Circular No. 13 del PRM, Francisca Córdova comunica a las autoridades civiles y militares, organizaciones obreras y campesinas y sector popular del estado de Sonora, su nombramiento como secretaria de

${ }^{47}$ Fondo Oficialía Mayor. Archivo Interno. Caja 48, exp. 234.3 “38”/3, 31 de diciembre de 1939. AGEs, México.

${ }^{48}$ Fondo Oficialía Mayor. Exp. 204.4 “42”/36). AGEs, México. 
Acción Femenil del Comité Ejecutivo Regional del PRM. La designación se le dio el 5 de noviembre de 1943. En el comunicado, Córdova señala lo siguiente: "Al hacerme cargo de esta importante Secretaría, lo hago animada de los mejores deseos, por que [sic] se me ha prestado la oportunidad que anhelaba para servir a la mujer de mi Estado, asegurándoles que mis palabras y promesas no resultarán estériles, sino que cumpliré fielmente con el Plan de Trabajo que se ha trazado el Comité Ejecutivo Regional del P.R.M.”. El comité ejecutivo del que formó parte Francisca lo encabezó el senador obregonista Alejo Bay, gobernador del estado de 1923 a $1927 .{ }^{49}$

Pocos años después, en 1948, encontramos a Córdova en la Secretaría de Acción Femenil, como única mujer dentro del comité ejecutivo de la Confederación de Organizaciones Populares (CNOP)..$^{50}$ En 1950 asume como secretaria de Acción Femenil del nuevo comité directivo del PRI. Continúa siendo la única mujer en ocupar un cargo. ${ }^{51} \mathrm{El}$ 6, 7 y 8 de agosto de 1953 se realizó el Congreso Nacional de la Mujer, previo a los debates del congreso donde se aprobaría el sufragio femenino el 17 de octubre. En julio, la Tesorería General del estado, por instrucciones del gobernador Ignacio Soto, gira una orden de pago al dirigente del PRI, Emeterio R. de Aguayo, por un monto de 8000 pesos para gastos de viaje de las cinco delegadas que asistirían al congreso. ${ }^{52}$ Otros recursos fueron otorgados por el gobernador para gastos preliminares del evento nacional. ${ }^{53}$ Es posible suponer que Francisca haya sido una de esas delegadas, pues en 1954 es la responsable en el estado del proceso de empadronamiento de las mujeres a las filas del PRI. El 8 de marzo de ese año, el gobierno le otorga 2500 pesos para "el empadronamiento de la mujer dentro de las filas del Partido Revolucionario Institucional" ${ }^{54}$ Poco después, la Tesorería le gira una nueva orden de pago, por otros 2500 pesos, para "la terminación del empadronamiento de miembros del sector femenil en el estado, a cargo de la Dirección de Acción Femenil". ${ }^{55}$

${ }^{49}$ Fondo Oficialía Mayor. Archivo Interno. s/n, tomo 29, exp. 215 “35”/36, 22 de diciembre 1943. AgES, México.

${ }^{50}$ Fondo Oficialía Mayor. Tomo 1775, exp. 215 “48”/5, 25 de febrero de 1948. AgEs, México.

${ }^{51}$ Fondo Oficialía Mayor. Tomo 1775, exp. 215 "48”/ 1, 18 de diciembre de 1950. AGEs, México.

${ }_{52}$ Fondo Oficialía Mayor. Tomo 2021, exp. 06 “53” /22, 22 de julio de 1953. AgEs, México.

${ }_{53}$ Fondo Oficialía Mayor. Tomo 2021, exp. 06. "53" /22, 20 de junio de 1953. AGEs. México.

${ }^{54}$ Fondo Oficialía Mayor. Exp. 331.26 "54" /1, 8 de marzo de 1954. AgEs, México.

${ }_{55}$ Fondo Oficialía Mayor. Exp. 331.26 “54” /1, 3 de junio de 1954. AgEs, México. 
Así quedó preparada la participación de las mujeres en el proceso electoral de 1955, donde Francisca, a pesar de su labor como operadora del instituto político para asegurar el voto femenino, apenas si obtuvo una suplencia en la diputación federal. Queda por analizar el rumbo que tomó su vida después de esa experiencia, si regresó a las filas de la dirigencia del priismo estatal o se le abrieron nuevos espacios partidarios a nivel nacional.

\section{A MANERA DE CONCLUSIONES}

Las sonorenses que aquí se abordan, no fueron "ángeles del hogar", como lo observa Porter (2006) al estudiar a las trabajadoras de la función pública. Como ellas, a través de su actividad laboral incursionaron en la política. Para algunas, la educación fue el vehículo fundamental para su movilidad social y su inmersión en el mundo de lo público. Fueron mujeres dinámicas cuyo activismo las llevó a reclamar derechos, y conseguirlos en algunos casos, pero manteniéndose siempre en los lindes de la subalternidad. La revolución y los conflictos por el poder que sobrevinieron posteriormente, les franqueó su paso a la contienda política. Para las fuerzas que se debatía el poder, las mujeres representan una mano de obra fundamental para potenciar sus avanzadas. Ellas supieron aprovechar esos resquicios que se les abrían construyendo con su actuación nuevas formas de subjetivarse como mujeres y como trabajadoras, validando con ello la presencia femenina en la esfera pública, como lo analiza Porter (2015) y Fernández (2014). Y, así como las mujeres estudiadas por Fernández (2014), las que aquí se abordan contribuyeron con su cuota a la institucionalización de la política partidista y la corporativización de las organizaciones sociales, entre ellas de manera central la de los sindicatos.

Aquí se han esbozado algunos retazos del arduo e incierto recorrido que trazaron algunas mujeres en Sonora hasta construir un protagonismo sindical y político relevante que les valió trascender las circunstancias que las rodearon para posicionarse en lo público. No lo tuvieron fácil, en un momento histórico falto de derechos ciudadanos y un contexto por demás adverso para el avance de las mujeres. Irrumpieron en el espacio público en la posrevolución aprovechando las coyunturas políticas que se les ofrecían, amoldándose a ellas, surcando barreras y abriendo caminos por los que fueron transitando hasta llegar, algunas, a un cargo administrativo, político o de elección popular; o alcanzar cierto reconocimiento posterior en la educación o el ámbito de las letras. 
Con todo y la adversidad, las maestras encontraron un camino menos escabroso que las trabajadoras, que no tenían más que su ingenio para traspasar las múltiples barreras. A pesar de su importante recorrido, poco se conoce de sus historias y de los obstáculos que enfrentaron. Las trayectorias de Enriqueta de Parodi y Catalina Acosta de Bernal tal vez sean las más conocida por su aporte literario. María Jesús Guirado por ser la primera mujer en ocupar una curul en el Congreso local. ¿Y las otras? No sólo me refiero a Dolores Enedina Cuiltre y Francisca Córdova, sino a las muchas otras que incursionaron en el magisterio o el sindicalismo no sólo para oficiar una profesión u ocupación, sino para enarbolar una postura o una protesta y situarse como las ciudadanas que el Estado posrevolucionario se negaba a reconocer.

Los distintos gobiernos que dirigieron el estado desde los años treinta hasta 1953, cuando se legisla el derecho al sufragio femenino, supieron aprovechar para su propio beneficio la capacidad que desplegaron las mujeres para la acción política. Con su participación, las mujeres intentaron de una u otra manera incidir en los asuntos públicos y en el ejercicio de la toma de decisiones. Algunas, como las cinco aquí señaladas, lograron acceder a cargos de incidencia política. Intentaron romper ciertos condicionantes de género y ser sujetos de su propia historia. Con todo, se mantuvieron en los espacios de poder que las reglas del juego político del momento les marcaron, disciplinándose al mismo tiempo que contenían posibles deseos de emancipación.

El derecho al voto en 1953 no incentivó la participación política de las mujeres en Sonora. Para entonces el corporativismo funcionaba con fuerza propia. Hubo de esperar el paso de algunos años para que nuevos acontecimientos comenzaran a mover la rueda de los cambios y convulsionaran de nuevo a la sociedad sonorense, con nuevas actoras en escena.

\section{LISTA DE REFERENCIAS}

Almada Bay, I. (1998). Casos de disimulo y clandestinidad en los años de la persecución religiosa en Sonora 1932-1936. En V. López Soto (coord.), Sonora: historia de la vida cotidiana (pp. 465-474). Hermosillo: Sociedad Sonorense de Historia, A. C. Almada Bay, I. (2009). La conexión Yocupicio. Soberanía estatal y tradición cívico-liberal en Sonora 1913-19. México: El Colegio de México. 
Aragón Pérez, R. (2003a). La enseñanza secundaria en Sonora. En R. Aragón Pérez (comp.), Historia de la educación en Sonora (t. 3, pp. 72-76). México: Gobierno del Estado de Sonora.

Aragón Pérez, R. (2003b). Las Misiones Culturales en Sonora. En R. Aragón Pérez (comp.), Historia de la educación en Sonora (t. 3, pp. 82-85). México: Gobierno del Estado de Sonora.

Bustamante Ortega, A. (1998). La educación de las mujeres en el porfiriato. En V. López Soto (coord.), Sonora: historia de la vida cotidiana (pp. 263-269). México: Gobierno del Estado de Sonora.

Cano, G. (1991). Las feministas en campaña. La primera mitad del siglo xx. Debate Feminista, 4, 269-292. DoI: https://doi.org/https://doi.org/10.22201/ cieg.2594066xe.1991.4.1536

Cano, G. (1996). Más de un siglo de feminismo en México. Debate Feminista, 14, 345359. DoI: https://doi.org/https://doi.org/10.22201/cieg.2594066xe.1996.14.353

Cejudo Ramos, E. (2008a). El legado de Enriqueta, a 111 años (Parte 1). Portales, 7(256). Recuperado de http://portales.colson.edu.mx/anteriores/256/

Cejudo Ramos, E. (2008b). El legado de Enriqueta de Parodi a 111 años de su nacimiento, parte 2. Portales, 7(258). Recuperado de http://portales.colson.edu.mx/ anteriores $/ 258$

Cejudo Ramos, E. (2009). Catalina. Portales, 8 (288). Recuperado de http://portales. colson.edu.mx/anteriores/288/

Cejudo Ramos, E. (2013). Mujer, periodismo y opinión en Sonora. El caso de los periódicos El Pueblo y El Tiempo de Hermosillo (1934-1938). México: El Colegio de Sonora.

Cejudo Ramos, E. (2019). Ciudadanas y católicas: mujeres laicas organizadas contra la campaña desfanatizadora de Sonora (1932-1939). (Tesis de doctorado). Universidad Nacional Autónoma de México, México.

Enríquez Licón, D. E. (1987). Sonora: Sindicatos y participación política (1932-1951). En Memorias del XII Simposio de Historia y Antropología de Sonora (vol. 1, pp. 86-103). Hermosillo: Instituto de Investigaciones Históricas-Universidad de Sonora.

Escobosa Gámez, G. (1995). Hermosillo en mi memoria. México: Instituto Sonorense de Cultura.

Estrella, E. (10 de mayo de 2015). Cuando el Itson llegó a Navojoa. Recuperado de https://www.infocajeme.com/universitaria/2015/05/cuando-el-itson-llego-a-navojoa/

Fernández Aceves, M. T., Ramos Escandón, C. y Porter, S. S. (2006). Los debates en torno a la historia de mujeres y la historia de género. En M. T. Fernández Aceves, C. Ramos Escandón y S. Porter (coords.), Orden social e identidad de género. México, 
siglos XIX y XX (pp. 11-33). México: Centro de Investigaciones y Estudios Superiores en Antropología Social/Universidad de Guadalajara.

Fernández Aceves, M. T. (2014). Mujeres en el cambio social en el siglo xx mexicano. México: Centro de Investigaciones y Estudios Superiores en Antropología Social/ Siglo XXI Editores.

François, M. (2015). La lavandería, la producción cultural y la economía política en la ciudad de México. En S. S. Porter, M. T. Fernández Aceves (eds.), Género en la encrucijada de la historia social y cultural de México (pp. 33- 65). México: El Colegio de Michoacán/Centro de Investigaciones y Estudios Superiores en Antropología Social.

Goldsmith Connelly, M. (2006). Política, trabajo y género: la sindicalización de las y los trabajadores domésticos y el Estado mexicano. En M. T. Fernández Aceves, C. Ramos Escandón y S. Porter (coords.), Orden social e identidad de género. México, siglos XIX y XX (pp. 215-244). México: Centro de Investigaciones y Estudios Superiores en Antropología Social/Universidad de Guadalajara.

Hernández, S. (2015). Las obreras de Monterrey. Trabajo y activismo femenino en la industria de la ropa, 1930-1940. En S. S. Porter, M. T. Fernández Aceves (eds.), Género en la encrucijada de la historia social y cultural de México (pp. 149-178). México: El Colegio de Michoacán/Centro de Investigaciones y Estudios Superiores en Antropología Social.

Lau, A. (2006). Expresiones políticas femeninas en el México del siglo xx: el Ateneo Mexicano de Mujeres y la Alianza de Mujeres de México (1934-1953). En M. T. Fernández Aceves, C. Ramos Escandón y S. Porter (coords.), Orden social e identidad de género. México, siglos XIX y Xx (pp. 93-124). México: Centro de Investigaciones y Estudios Superiores en Antropología Social/Universidad de Guadalajara.

López Romero, J. C. J. (2016). La rebelión de los pupitres. Movimiento magisterial en Sonora. 1959-1960. (Tesis de licenciatura). Universidad de Sonora, México.

Moncada, C. (1988). La sucesión política en Sonora 1917-1985. Hermosillo: Editorial Latinoamericana.

Porter, S. (2006). Espacios burocráticos, normas de feminidad e identidad de la clase media en México durante la década de 1930. En M. T. Fernández Aceves, C. Ramos Escandón y S. Porter (coords.), Orden social e identidad de género. México, siglos XIX y XX (pp. 189-213). México: Centro de Investigaciones y Estudios Superiores en Antropología Social/Universidad de Guadalajara.

Porter, S. S. (2015). De obreras y señoritas. Culturas de trabajo en la ciudad de México en la compañía Ericsson, en la década de 1920. En S. S. Porter, M. T. Fernández Aceves (eds.), Género en la encrucijada de la historia social y cultural de México (pp. 
179-210). México: El Colegio de Michoacán/Centro de Investigaciones y Estudios Superiores en Antropología Social.

Reñique, G. (2003). Región, raza y nación en el antichinismo sonorense. Cultura regional y mestizaje en el México posrevolucionario. En A. Grageda (coord.), Seis expulsiones y un adiós. Despojos y exclusiones en Sonora. México: Plaza y Valdés.

Robles, S. (2015). "El Club de la Escoba y el Plumero" y la creación de un espacio público. Las mujeres en la radio mexicana, 1921-1950. En S. S. Porter, M. T. Fernández Aceves (eds.), Género en la encrucijada de la historia social y cultural de México (pp. 211-232). México: El Colegio de Michoacán/Centro de Investigaciones y Estudios Superiores en Antropología Social.

Trueba Lara, J. L. (1990). Los chinos en Sonora: una historia olvidada. Hermosillo: Cuadernos del Instituto de Investigaciones Históricas No. 2, Unison.

Valdez Villareal, R. (2008). Historia del plantel Álamos. México: El Colegio de Bachilleres.

Vaughan, M. K. (2001). La política cultural en la revolución. Maestros, campesinos y escuelas en México, 1930-1940. México: FCE.

Zatarain Valdez, M. (24 de diciembre de 2011). La escuela secundaria Othón Almada de Navojoa, Sonora. http://laescuelasecundariaothonalmada.blogspot.com/

Zúñiga Elizalde, M., Cejudo Ramos, E., Acedo Ung, L. (2013). Sonora, 1925-1954. En A. Lau Jaiven y M. Zúñiga Elizalde (coords.), El sufragio femenino en México. Voto en los estados (1917-1965) (pp. 207-233. México: El Colegio de Sonora.

Zúñiga Elizalde, M., Cejudo Ramos, E., Acedo Ung, L. (2014). Participación sindical de las mujeres sonorenses en el periodo posrevolucionario (1925-1954). En S. López Estrada y C. Quintero Ramírez (coords.), Los estudios de género en el norte de México a umbrales del siglo XxI. (pp. 197-218). México: El Colegio de la Frontera Norte.

Zúñiga Elizalde, M. (2018). Emélida Carrillo: las contradicciones de una feminista en las postrimerías de la revolución mexicana. En A. Lau Jaiven y E. Mac Phail Fanger (coords.), Rupturas y continuidades. Historia y biografías de mujeres (pp. 111-141). México: Universidad Autónoma Metropolitana, unidad Xochimilco.

Zúñiga Elizalde, M. (2020). Irrupción pública de las mujeres en la posrevolución sonorense. En M. Zúñiga Elizalde, E. Cejudo Ramos y L. Acedo Ung (coords.), Mujeres y participación pública en Sonora. De la exclusión a la paridad electoral (18902018). México: El Colegio de Sonora. 


\section{OTRAS FUENTES}

Archivos

Ages Archivo General del Estado de Sonora, México. 